\title{
Influence of optical radiation and magnetic field on the properties of $\mathrm{InSe}<\mathrm{NaNO}_{2}>$ clathrate
}

\author{
${ }^{1}$ Dupliak I., ${ }^{2,3}$ Ivashchyshyn F., ${ }^{2}$ Całus D., ${ }^{4}$ Seredyuk B., ${ }^{2}$ Chabecki P., \\ ${ }^{3}$ Maksymych V. and ${ }^{1 *}$ Fengping Li \\ ${ }^{1}$ Wenzhou University Institute of Laser and Optoelectronic Intelligent \\ Manufacturing, Ocean Science and Technology Innovation Park, No. 19 Binhai \\ $3^{\text {rd }}$ Road, Yongxing Street, Longwan District, Wenzhou, Zhejiang, China. \\ ${ }^{2}$ Czestochowa University of Technology, Faculty of Electrical Engineering, \\ Al. Armii Krajowej 17, Częstochowa, 42-200, Poland. \\ FedirIvashchyshyn@gmail.com \\ ${ }^{3}$ Lviv Polytechnic National University, 12 S. Bandera Street, 79013 Lviv, Ukraine \\ ${ }^{4}$ Hetman Petro Sahaidachnyi National Army Academy, 32 Heroes of Maidan Street, \\ 79026 Lviv, Ukraine
}

Received: 04.05 .2020

\begin{abstract}
We investigate the changes occurring in the physical properties of InSe single crystals as a result of $\mathrm{NaNO}_{2}$ intercalation. The degree of crystal-lattice expansion is analyzed. The properties of the original InSe single crystals and the two-fold or four-fold expanded crystals are examined. Moreover, we analyze the effect of quantum capacity on the process of current passage in case of the two-fold expanded $\mathrm{InSe}<\mathrm{NaNO}_{2}>$ clathrate under a constant magnetic field. The effect of 'negative capacitance' at the low frequencies of magnetic field in the two-fold expanded InSe $<\mathrm{NaNO}_{2}>$ clathrate is studied under conditions of illumination.
\end{abstract}

Keywords: intercalation, InSe, clathrates, nanohybrides, impedance spectroscopy.

UDC: $537.226 .8+535.21$

\section{Introduction}

Recently there has been a spark of interest in the formation of heterostructured inorganic/inorganic, inorganic/organic and bio/inorganic nanocomposites as a way of obtaining structures with a wide range of novel properties [1-5]. The common methods used to obtain these composites, e.g. vacuum deposition, photolithography and synthetic Langmuir-Blodgett technique, have certain drawbacks related to a limited variability of heterogeneous agents and the problems with synthesizing 'host-guest' architecture. Nonetheless, it is possible to achieve a directed change in the original atomic-molecular structure of the 'host' materials, to form it at the atomic-molecular level and to build the whole functional blocks with certain structures. This can be done by intercalation of guest components into a crystalline structure, using van der Waals forces of the 'host' materials.

In order to construct an operating basis for the supra-molecular design of structures [6, 7], it is necessary to know the properties of the initial ingredients, their changes as they get intercalated into host materials, and the changes occurring in the behaviour of guest materials due to modifications of their crystalline structure or peculiarities of the nano-limited guest geometry [8-11].

The fundamental questions of dimensional effects on the ferroelectric polarization are the existence of critical size of ferroelectric domains, the changes in the Curie temperature, etc. [12, 13].

*Corresponding author: 1fp@wzu.edu.cn

Ukr. J. Phys. Opt. 2020, Volume 21, Issue 3 
The intercalation technologies give the opportunity to control the size and the mutual arrangement of ferroelectric phases introduced due to formation of different geometries of the guest areas.

The behaviour of $\mathrm{NaNO}_{2}$ ferroelectric at quasi-two-dimensional guest positions in a p-type semiconductor has earlier been examined in our work [14]. The kinetic characteristics of current passage and the polarization processes in $\mathrm{GaSe}<\mathrm{NaNO}_{2}>$ clathrates synthesized with different degrees of expansion have been studied in this work. A significant effect of the guest nanogeometry on the characteristics of $\mathrm{GaSe}<\mathrm{NaNO}_{2}>$ clathrates under normal conditions and in external electromagnetic fields has been demonstrated. In particular, the clathrate structure of synthesized hybrids enables achieving giant photo-dielectric, magneto-resistive and magnetocapacitant effects at the room temperature. Moreover, co-intercalation of a ferroelectric with a ferromagnet in GaSe allows one to implement a quantum amplification of magnetic sensitivity. In Refs. $[14,15]$ we have focused on the prospects of synthesized clathrates to create nanoscale current sources. Besides, a high-resistance-to-low-resistance switching effect occurring at the frequencies that exceed $\sim 5.3 \times 10^{3} \mathrm{~Hz}$ has been demonstrated for the cointercalant clathrate $\mathrm{InSe}<\mathrm{NaNO}_{2}+\mathrm{FeSO}_{4}>[15]$.

The main purpose of the present work is to investigate the properties of ferroelectric phase placed in quasi-two-dimensional guest positions of photosensitive n-type semiconductor $\operatorname{InSe}$ matrix. Similarly to the work [14], we employ the intercalation technologies to form an InSe $<\mathrm{NaNO}_{2}>$ clathrate with two- and four-fold expansions of the crystalline matrix and, in this manner, we study the dimensional effects. More specifically, this work is devoted to the studies of electrical resistivity and polarization properties of the clathrates.

\section{Experimental techniques}

We have chosen InSe as a host material. InSe single crystals produced by a Bridgman-Stokbarger technique have a layered structure and n-type of conductivity. According to the optical data, their bandgap is equal to $1.20 \mathrm{eV}$. It is well-known (see, e.g., Ref. [13]) that the InSe single crystals are characterized by the presence of 'guest' positions. These are the regions with weak Van der Waals forces, which are oriented perpendicular to the crystallographic axis $c$. This circumstance enables intercalation of ions, atoms or molecules into some intra-crystalline spaces [16]. Moreover, the single crystals are characterized by high photosensitivity in the visible spectral range.

The choice of $\mathrm{NaNO}_{2}$ as a guest ferroelectric is vindicated by its ability to intercalate directly single crystals of InSe due to the presence of unpaired electrons at nitrogen atoms in the molten state. Therefore, formation of the $\mathrm{InSe}<\mathrm{NaNO}_{2}>$ clathrate has been carried out by directly exposing InSe in a melt of $\mathrm{NaNO}_{2}$ at the temperature $300^{\circ} \mathrm{C}$. As a result, $\mathrm{NaNO}_{2}$ has become intercalated in between InSe layers. Different exposure time intervals have provided a given multiplicity of expansion and a degree of guest load. The peculiarity of the approach applied by us is that the content of guest $\mathrm{NaNO}_{2}$ is the same for the cases of two- and four-fold expansions. According to the weight of intercalation, it amounts to $5 \%$.

The impedance was measured in the range $10^{-3}-10^{6} \mathrm{~Hz}$, using an "Autolab" measuring complex manufactured by the company "Eco Chemie", with software packages FRA-2 and GPES. The amplitude of applied sinusoidal signal did not exceed $5 \mathrm{mV}$. The ambiguous points were removed using a Dirichlet's filter $[17,18]$. The frequency dependences of the complex impedance $Z$ were analyzed by a graph-analytical method using software package ZView 2.3 (Scribner Associates). The impedance models constructed from the experimental data package were confirmed by the complete randomness of the frequency dependences of the first-order residual 
differences $[17,18]$. The fitting errors did not exceed $4 \%$. The impedance dependences were also measured in a constant magnetic field $(2.75 \mathrm{kOe})$ and under visible light (a halogen source with the power $65 \mathrm{~W}$ and the candle power $1200 \mathrm{~cd}$ ) propagating along the crystallographic axis $c$. The spectroscopes of thermo-stimulated depolarization were recorded in the mode of short-circuited contacts with the linear heating performed at the rate $5^{\circ} \mathrm{C} / \mathrm{min}$.

\section{Results and discussion}

Crystalline-lattice intercalation of InSe single crystals by $\mathrm{NaNO}_{2}$ leads to notable changes in their physical properties. These changes depend on the degree of expansion of crystal lattice as a result of intercalation. Therefore, the original InSe single crystals and the crystals with the two-fold and four-fold expansions have been investigated in order to compare their properties.

To clarify the structural changes occurring in InSe due to crystalline lattice expansion, we have used X-ray diffraction. Fig. 1 shows the curves of reflection from the packets of atomic layers, which are separated by enlarged van der Waals spacings, for InSe with different degrees of expansion. A number of structural changes can be observed as a result of expanding. In particular, clear displacement of the angular maximum towards larger scattering angles is observed (see Fig. 1).

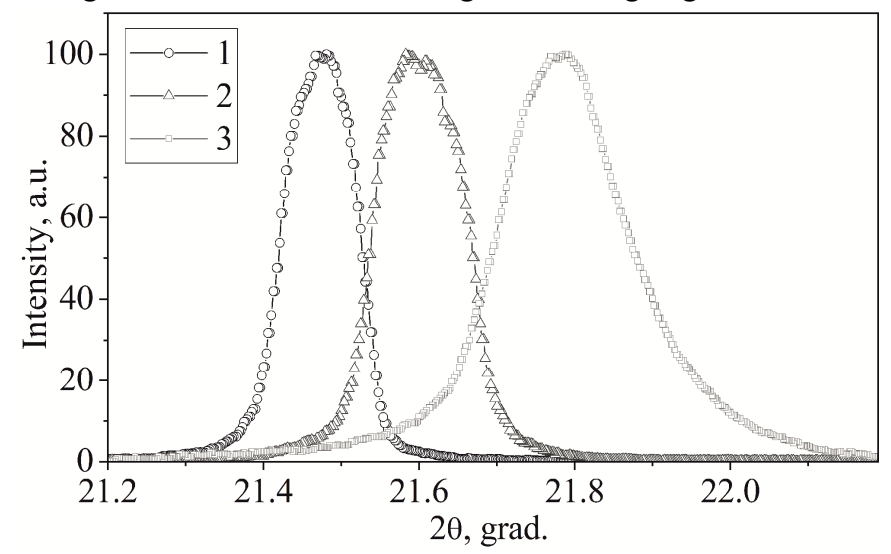

Fig. 1. X-ray diffraction reflection curves (004) for the InSe single crystals, as measured for the non-expanded sample (1) and two-fold (2) and four-fold (3) expanded samples.

According to the Bragg's law, we have

$$
d_{(n k l)}=\lambda / 2 \sin (\theta),
$$

where $\lambda=1.5418 \AA$ is the wavelength of $\mathrm{CuK}_{\alpha}$-radiation. This displacement is caused by a reduction of interlayer distance $d_{(004)}$ and a gap arising among the layers in unexpanded InSe structures. The numeric value of the Bragg angle allows us to determine the parameter $c$ of the elementary cell of InSe:

$$
c=l \times d_{(h k l)}=4 \times d_{(004)} .
$$

The dependence of the $c$ parameter on the expansion degree is shown in Fig. 2. There is a pronounced decrease in the cell parameter along the direction perpendicular to the layers with increasing expansion factor.

A shift in the angular position of the Bragg's maximum and increase in the half-width of diffraction reflection curves take place, if compared to the original sample (see Fig. 2). A wellknown equation for the relative change in inter-planar distance follows from the Bragg's law:

$$
\frac{\Delta d}{d}=-\operatorname{ctg}(\theta) \times \Delta \theta .
$$




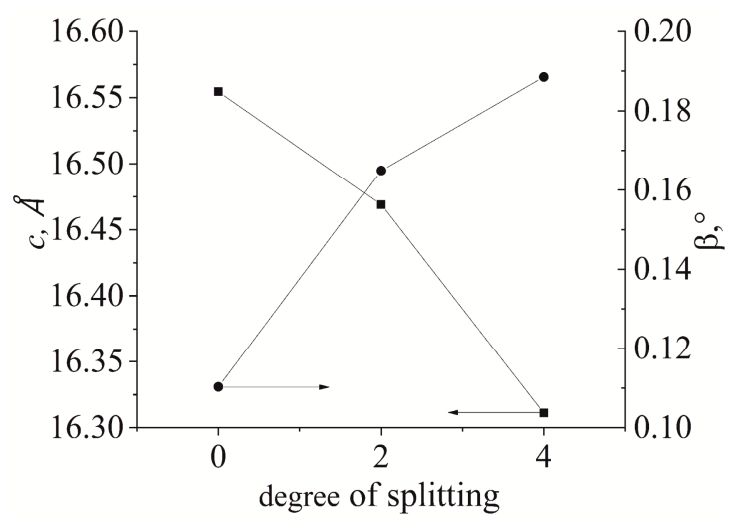

Fig. 2. Dependences of cell parameter and half-width of the X-ray diffraction reflection curves $\beta$ on the degree of expansion in the InSe single crystals.

The expansion of the reflection curves is proportional to the relative change in the interplanar distance. It indicates a presence of fluctuations in the distances among the layers. Fig. 2 also illustrates the changes in the half-width of the reflection curves owing to four-fold extension. Namely, the half-width of the curve becomes almost doubled.

As a result of single-crystal expansion, an $N$-stage-ordered structure is formed. It consists of identical packets (with compressed interlayer distances, when compared to the original single crystal), which are separated by extended regions.

The conductive properties of the original InSe single crystals have been studied using the impedance spectroscopy method. The frequency dependences of the real part of complex resistance are presented in Fig. 3. The measurements have been carried out under normal conditions, in a constant magnetic field, and under illumination.

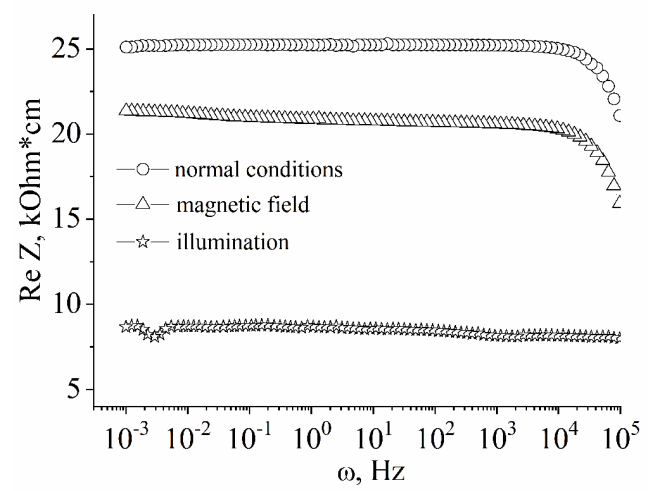

Fig. 3. Frequency dependences of real impedance component for the original InSe single crystal under normal conditions, in a constant magnetic field and under illumination (see legend).

Under normal conditions, we obtain a typical behaviour of $\operatorname{Re} Z(\omega)$ characterized by a pronounced frequency dependence in the range of $10^{-3}-10^{4} \mathrm{~Hz}$. The constant magnetic field imposes $15 \%$ reduction of $\operatorname{Re} Z$, with no changes in the shape of frequency dependence. This can result from delocalization of charge carriers by the magnetic field due to Zeeman effect. A significant decrease in $\operatorname{Re} Z$ (some 65\%) under illumination can be readily expected due to photosensitive properties of the InSe single crystals. A minimum observed in the low-frequency region (see Fig. 3) indicates the presence of a narrow band of deep traps that release captured electrons at low frequencies under the influence of light. 
The Nyquist diagram obtained for the InSe single crystals under normal conditions (see Fig. 4) has an expected semicircle shape. The equivalent electric circuit for this case is represented in the insert (a) of Fig. 4. Since the centre of the semicircle does not lie on the $\operatorname{Re} Z$ axis, a constant phase element [17] is involved in the equivalent circuit. It simulates distributed capacity due to the presence of vacancies or impurity defects that induce conductivity of the clathrate at room temperature. The difference between the Nyquist diagrams measured under a constant magnetic field and under illumination (see Fig. 4) is a horizontal linear branch directed towards $\operatorname{Re} Z$ increase at low frequencies. This behaviour is represented by an bounded constant phase element [17] (see the insert (b) in Fig. 4), which simulates electric current flow in a spatially-restricted area with a complex electrical conductivity.

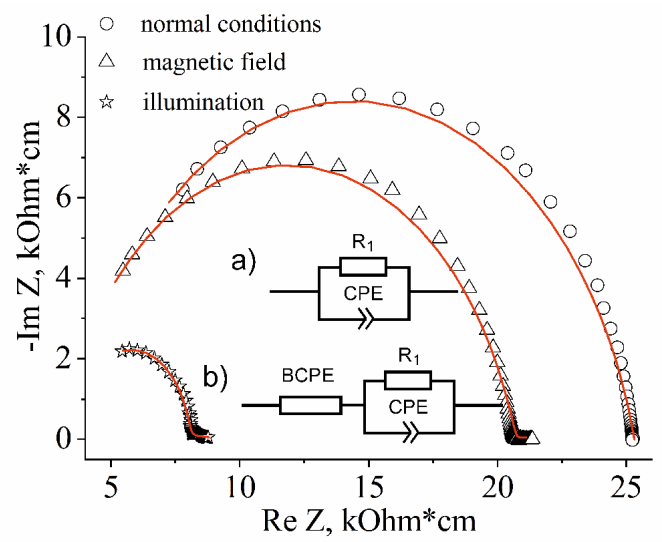

Fig. 4. Nyquist diagrams for the InSe single crystals under normal conditions (a), in a constant magnetic field (b) and under illumination (see legend). Points and lines correspond to experimental and modelled data. Inserts represent equivalent electric circuits for the hodograph.

The impedance of the InSe $<\mathrm{NaNO}_{2}>$ clathrates with the two-fold expanded crystalline lattice is shown in Fig. 5. A comparison of $\operatorname{Re} Z(\omega)$ values measured for the original InSe single crystals (see Fig. 3) and the two-fold expanded $\mathrm{InSe}<\mathrm{NaNO}_{2}>$ clathrate (see Fig. 5) testifies that intercalation of $\mathrm{NaNO}_{2}$ leads to five-fold decrease in the resistance of the latter, with almost no change in the shape of the frequency behaviour of $\operatorname{Re} Z(\omega)$.

However, a constant magnetic field reduces $\operatorname{Re} Z(\omega)$ by $40 \%$ (see Fig. 5), when compared to original InSe. An anomalous $\operatorname{Re} Z$ increase in the low-frequency range $\left(10^{-3}-1 \mathrm{~Hz}\right)$ is worth noticing. This phenomenon is associated with band carriers. It points to the effect of Lurry

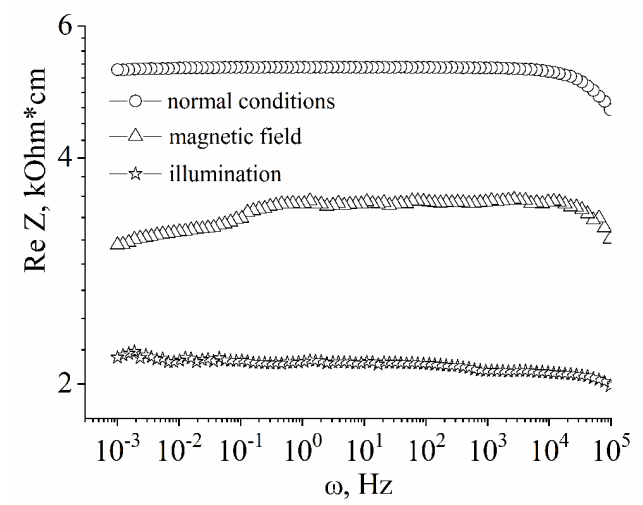

Fig. 5. Frequency dependences of real impedance component for the two-fold expanded InSe $<\mathrm{NaNO}_{2}>$ clathrate under normal conditions, in a constant magnetic field and under illumination (see legend). 
quantum capacity [19] for discrete states along the direction perpendicular to nanoparticles. Quantum capacitance in this case is induced by a constant magnetic field. The intercalation of $\mathrm{NaNO}_{2}$ does not lead to significant changes in the photosensitivity of the clathrate (the $\mathrm{Re} Z$ value decreases by $60 \%$ - see Fig. 5$)$, but induces $\operatorname{Re} Z(\omega)$ oscillations at low frequencies. This may indicate a 'negative capacity' effect. The observed phenomenon is associated with photoexcitation of electrons from the occupied states below the Fermi level and, hence, with formation of trap centres for the injected electrons with the relaxation time greater than the half-period of sinusoidal signal [20-23].

Under normal conditions, the Nyquist diagram for the two-fold expanded $\operatorname{InSe}<\mathrm{NaNO}_{2}>$ clathrate (see Fig. 6) is characterized by two overlapped semicircles, which are represented by the corresponding parallel links of the equivalent electric circuit (see the insert (a) in Fig. 6). In this circuit, the high-frequency $R_{1} / C P E$ component reflects the current passage in the unexpanded packets of matrix with localized states in the vicinity of the Fermi level, while the low-frequency $R_{2} / C P E$ component is responsible for the inter-packet charge transfer. A horizontal branch appears under the constant magnetic field, which is directed towards $\operatorname{Re} Z$ decrease. This feature is reflected in the equivalent electrical circuit as a quantum capacity $C_{Q}$ (see the insert (b) in Fig. 6). Under illumination, the impedance goes into the fourth quadrant of the complex plane. This is represented by an inductance $L$ in the equivalent electric circuit (see the insert (c) in Fig. 6). This $R_{1} / L C$ link simulates charge transfer through the phases interface. Note that the inductance $L$ obtained by us is about $300 \mathrm{H}$, though it is generated by the visible light. This fact opens some prospects for applications of our nanostructure in electronics.

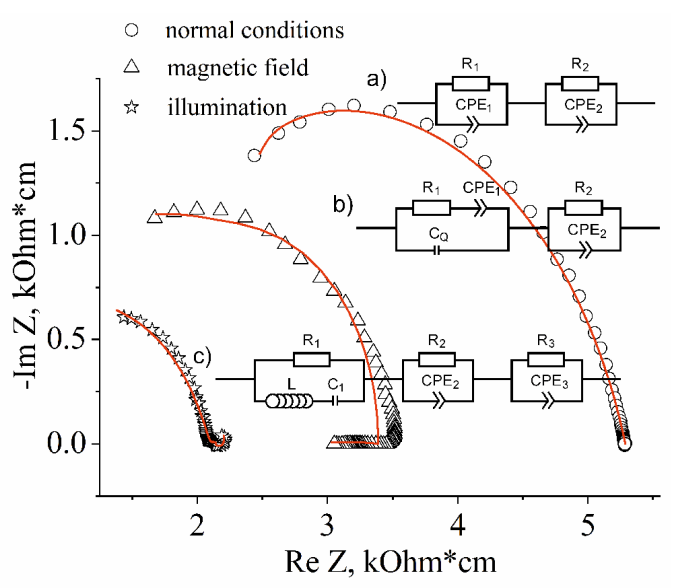

Fig. 6. Nyquist diagrams for the two-fold expanded InSe $<\mathrm{NaNO}_{2}>$ clathrate under normal conditions (a), in a constant magnetic field (b) and under illumination (c). Points and lines correspond respectively to experimental and modelled data. Inserts represent equivalent electric circuits for the hodograph.

The impedance data for the $\mathrm{InSe}<\mathrm{NaNO}_{2}>$ intercalation in the case of four-fold expansion of crystalline lattice is displayed in Fig. 7. Comparing the $\operatorname{Re} Z(\omega)$ values measured for the original InSe single crystals (see Fig. 3) with those of the four-fold $\mathrm{InSe}<\mathrm{NaNO}_{2}>$ clathrate (see Fig. 7), one can see that introduction of $\mathrm{NaNO}_{2}$ leads to increase, by 1.8 times, in the electrical resistance of the inter-calant. Moreover, the character of the frequency $\operatorname{Re} Z(\omega)$ dependence changes. The electrical resistance of the four-fold $\mathrm{InSe}<\mathrm{NaNO}_{2}>$ clathrate increases 1.8 times (see Fig. 7), while the shape of the $\operatorname{Re} Z(\omega)$ curve changes essentially, if compared to the original InSe single crystals (see Fig. 3). The reason is introduction of $\mathrm{NaNO}_{2}$ in the crystalline lattice of $\operatorname{InSe} \operatorname{ReZ}(\omega)$ takes a downward trend due to creation of internal fields of electret polarization by the guest component. 
This causes localization of electrons at the states near the Fermi level and, accordingly, a frequency dependent behaviour of the impedance hodograph. Further increase in the $\operatorname{Re} Z$ value by $12 \%$ appearing under the constant magnetic field is quite expected due to the Zeeman effect. The photosensitivity of the original crystalline matrix in InSe is completely levelled in this clathrate (see Fig. 7). The illumination induces a slight increase (3\%) in the $\operatorname{Re} Z$ value, though the $\operatorname{Re} Z(\omega)$ dependence acquires a frequency-dependent character. In this case one can claim a 'suppression' of the properties of InSe crystalline matrix by the $\mathrm{NaNO}_{2}$ intercalate.

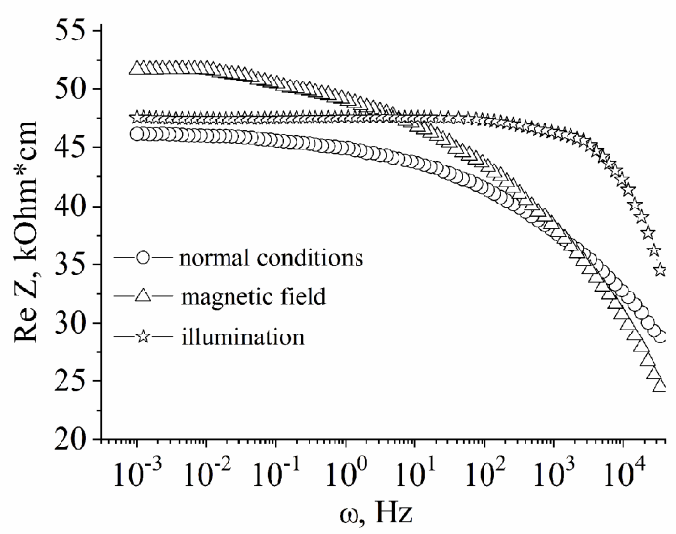

Fig. 7. Frequency dependences of real impedance component for the four-fold expanded InSe<NaNO $\mathrm{N}_{2}>$ clathrate under normal conditions, in a constant magnetic field and under illumination (see legend).

The Nyquist diagrams presented in Fig. 8. confirm the assumptions made above. The twoarched behaviour becomes more pronounced, and the corresponding equivalent scheme remains the same for the measurements performed under normal conditions, constant magnetic field and illumination.

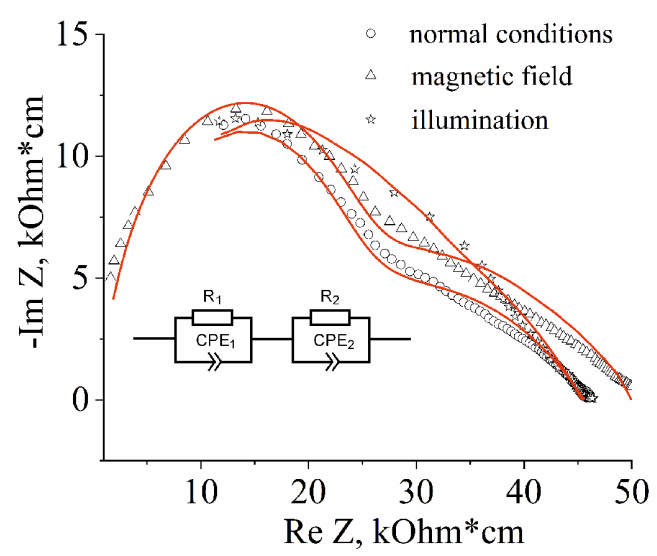

Fig. 8. Nyquist diagrams for the four-fold expanded InSe $<\mathrm{NaNO}_{2}>$ clathrate under normal conditions, in a constant magnetic field and under illumination (see legend). Points and lines correspond respectively to experimental and modelled data. Insert represents equivalent electric circuit diagram for all hodographs.

Fig. 9 compares frequency behaviours of the imaginary component of complex impedance for the unexpanded InSe single crystals with the two- and four-fold expanded InSe $<\mathrm{NaNO}_{2}>$ clathrates. A clear shift in the $-\operatorname{Im} Z(\omega)$ maximum towards higher frequencies is observed for the original (unexpanded) single crystals studied under illumination (see Fig. 9a). This confirms our statement about the existence of deep trap centres. 


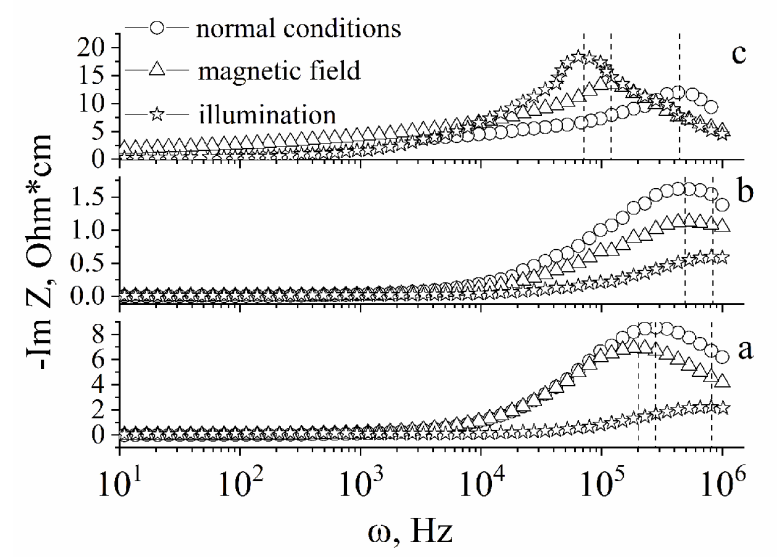

Fig. 9. Frequency dependences of imaginary impedance component for the original InSe single crystals (a), the two-fold (b) and four-fold (c) expanded InSe $<\mathrm{NaNO}_{2}>$ clathrates under normal conditions, in a constant magnetic field and under illumination (see legend).

The intercalation of $\mathrm{NaNO}_{2}$ in the two-fold expanded $\mathrm{InSe}<\mathrm{NaNO}_{2}>$ clathrate shifts the $\operatorname{Im} Z(\omega)$ maximum towards higher frequencies, thus indicating the additional impurity levels, which appear in the forbidden zone and are formed due to intercalation of the guest component. The position of the $-\operatorname{Im} Z(\omega)$ maximum under illumination does not change (see Fig. 9b). The $\operatorname{ImZ}(\omega)$ maximum for the four-fold expanded $\operatorname{InSe}<\mathrm{NaNO}_{2}>$ clathrate remains practically unchanged. However, it is strongly shifted by either magnetic field or illumination towards lower frequencies (see Fig. 9c). Such behaviour may imply formation of a broad band of localized states around the Fermi level.

The current spectra illustrating thermally stimulated discharge process are shown in Fig. 10. Here the measurements have been performed at short-circuited contacts. The unexpanded InSe single crystals are characterized by a narrow strip with low density of states and a well-defined mini-zone character (see Fig. 10a). The intercalation of $\mathrm{NaNO}_{2}$ in the two-fold expanded InSe matrix causes formation of coordination defects, of which structure is different from that of the original matrix, with positive correlation energy. This forms a quasi-continuous spectrum of localized states in the forbidden band (see Fig. 10b). In the both cases, there is a relaxation of homo-charge. In the case of four-fold expanded $\mathrm{InSe}<\mathrm{NaNO}_{2}>$ clathrate, a broad band of localized states is formed near the Fermi level, with a significantly higher density of states. There is a relaxation of both homo- and hetero-charges (see Fig. 10c).

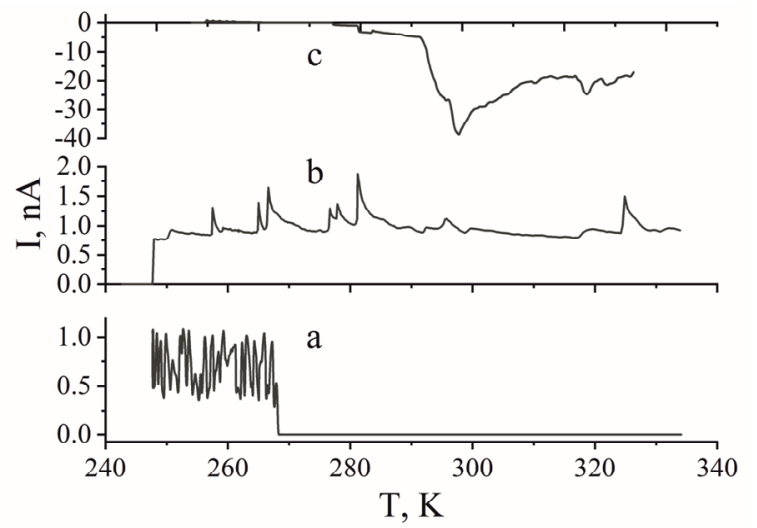

Fig. 10. Current spectra of stimulated discharge thermals, as measured for the original InSe single crystals (a), the two-fold (b) and four-fold (c) expanded InSe $<\mathrm{NaNO}_{2}>$ clathrates. 
The impurity energy spectrum has been calculated basin on the Jebol-Pollack theory [24]. The results are presented as histograms in Fig. 11. The actual density of deep traps $N_{t}$ and the length of the hop of electron $r$ do not change for all of the three cases. Nonetheless, the distribution of trap centres $J$ after intercalation of $\mathrm{NaNO}_{2}$ is reduced by almost twice, whereas the density of states at the Fermi level $N(F)$ is almost doubled.
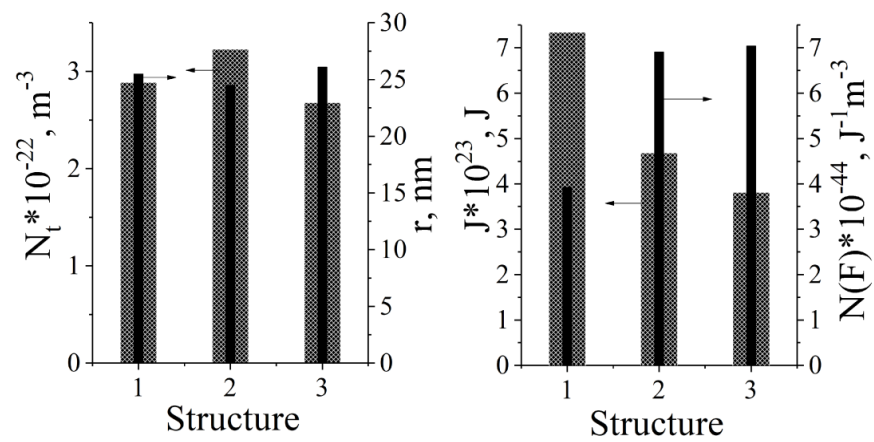

Fig. 11. Real density $N_{t}$ of deep traps, length $r$ of the electron jumps, scattering $J$ of the trap centres, density of states $N(F)$ at the Fermi level versus the structure: the original InSe single crystal (1), the two-fold (2) and fourfold (3) expanded InSe $<\mathrm{NaNO}_{2}>$ clathrates.

In order to confirm the formation of electret polarization by the guest component in the fourfold expanded $\mathrm{InSe}<\mathrm{NaNO}_{2}>$ clathrate, we have investigated its polarization properties. When analyzing the dielectric constant of this clathrate, we have taken into account only the values for which the tangent angle of the electrical losses is less than unity. Such a measure corresponds to the four-fold expanded $\mathrm{InSe}<\mathrm{NaNO}_{2}>$ clathrate under constant magnetic field or under illumination. In this case the dielectric constant at $10^{5}-10^{6} \mathrm{~Hz}$ behaves anomalously and manifests a maximum value $\sim 4000$.

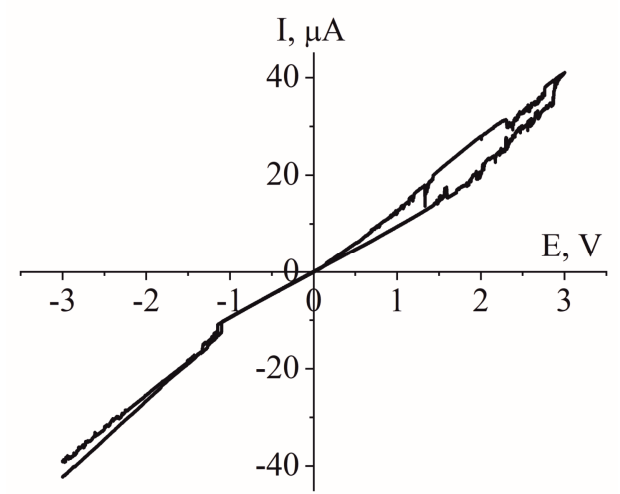

Fig. 12. Volt-ampere characteristic obtained for the four-fold expanded InSe $<\mathrm{NaNO}_{2}>$ clathrate under normal conditions.

The volt-ampere characteristic for the four-fold expanded $\mathrm{InSe}<\mathrm{NaNO}_{2}>$ clathrate measured under normal conditions is shown in Fig. 12. A quasi-linear behaviour has been obtained for the InSe single crystals and the two-fold expanded $\mathrm{InSe}<\mathrm{NaNO}_{2}>$ clathrate. In case of the four-fold expanded InSe $<\mathrm{NaNO}_{2}>$ clathrate, the volt-ampere characteristic is radically different and acquires a hysteresis character (see Fig. 12). This implies that the processes of charge accumulation take place at the inter-phase boundaries [25].

\section{Conclusion}

As a result of our studies, the following main conclusions can be drawn.

1. A five-fold decrease in the electrical resistance observed for the two-fold expanded $\mathrm{InSe}<\mathrm{NaNO}_{2}>$ clathrate due to delocalized carriers is caused by significant transformation of 
the impurity energy spectrum. With the same contents of the guest content, only 1.8-fold increase is observed for the electric resistance of the four-fold expanded $\operatorname{InSe}<\mathrm{NaNO}_{2}>$ clathrate. This is associated with the formation of electret polarization of the guest component.

2. A non-monotonic character of the low-frequency $\operatorname{Re} Z(\omega)$ branch, which results in the 'negative capacitance' effect, is peculiar for the two-fold expanded $\operatorname{InSe}<\mathrm{NaNO}_{2}>$ clathrate under illumination.

3. A significant contribution to the process of current passage in the two-fold expanded InSe $<\mathrm{NaNO}_{2}>$ clathrate under a constant magnetic field is made by the quantum capacity.

4. The current-voltage characteristic for the four-fold expanded $\mathrm{InSe}<\mathrm{NaNO}_{2}>$ clathrate has a hysteretic character. It is fundamentally different from the quasi-linear behaviour typical for both the initial InSe single crystals and the two-fold expanded $\mathrm{InSe}<\mathrm{NaNO}_{2}>$ clathrate. This fact testifies accumulation of electric charge at the inter-phase boundaries.

\section{References}

1. Choy J H, 2004. Intercalative route to heterostructured nanohybrid. J. Phys. Chem. Sol. 65: 373-383.

2. Solís-Fernández P, Bissett $\mathrm{M}$ and Ago H, 2017. Synthesis, structure and applications of graphene-based 2D heterostructures. Chem. Soc. Rev. 46: 4572-4613.

3 Mashtalir O, Naguib M, Mochalin V N, Dall'Agnese Y, Heon M, Barsoum M W and Gogotsi $\mathrm{Y}$, 2013. Intercalation and delamination of layered carbides and carbonitrides. Nature Commun. 4: 1716.

4. Balaban O V, Grygorchak I I, Kondyr A I, Zaichenko O S, Mitina N E, Datsyuk V V, Trotsenko S E and M'yahkota O S, 2017. Investigation of the planar structures of quantum functional polymeric nanolayers on polybenzimidazole fiber nanosheets. Mater. Sci. 53: 179-185.

5. Balaban O, Grygorchak I, Mitina N, Zaichenko A, Lukiyanets B, Glasunova V, Borysiuk A, Larkin M, Hevus O, Pokladok N, Datsyuk V and Trotsenko S, 2019. Fabrication of 1Dnanofiber $/ \mathrm{Fe}_{2} \mathrm{O}_{3}$ composites with tailored magnetic properties. J. Nanosci. Nanotechnol. 19: 3871-3878.

6. Yang L, Tan X, Wang Z and Zhang X, 2015. Supramolecular polymers: historical development, preparation, characterization, and functions. Chem. Rev. 115: 7196-7239.

7. Steed J W and Atwood J L. Supramolecular chemistry: $2^{\text {nd }}$ Ed.: John Wiley \& Sons (2009).

8. Tien C, Charnaya E V, Baryshnikov S V, Lee MK, Sun S Y, Michel D and Böhlmann W, 2004. Evolution of $\mathrm{NaNO}_{2}$ in porous matrices. Phys. Solid State. 46: 2301-2305.

9. Ushakov V V, Aronin A S, Karavanskiı̌ V A and Gippius A A, 2009. Formation and optical properties of CdSSe semiconductor nanocrystals in the silicate glass matrix. Phys. Solid State. 51: 2161.

10. Danishevskiı̌ A M, Kyutt R N, Sitnikova A A, Shanina B D, Kurdyukov D A and Gordeev S K, 2009. Palladium clusters in nanoporous carbon samples: structural properties. Phys. Solid State. 51: 640-644.

11. Baryshnikov S V, Charnaya E V, Milinskiǐ A Y, Stukova E V, Tien C and Michel D, 2010. Dielectric properties of crystalline binary $\mathrm{KNO}_{3}-\mathrm{AgNO}_{3}$ mixtures embedded in nanoporous silicate matrices. Phys. Solid State. 52: 392-396.

12. Fridkin V M, 2006. Critical size in ferroelectric nanostructures. Sov. Physics Uspekhi. 49: 193-202

13. Lies R M A, 1977. III-VI compounds. In: Preparation and crystal growth material with layered structure. Ed. Lies R M A, p. 225-254. 
14. Ivashchyshyn F, Grygorchak I and Hryhorchak O I, 2017. Influence of the degree of the expansion of the crystal lattice on properties and response to the electromagnetic fields of $\mathrm{GaSe}$ $<\mathrm{NaNO}_{2}>$ clathrate. Slovak Int. Sci. J. 5: 8-14.

15. Grygorchak I I, Ivashchyshyn F O, Lukiyanets B A and Kulyk Y O, 2017. Cointercalate semiconductors $\mathrm{GaSe}(\mathrm{InSe})$ with guest multiferroic $\mathrm{NaNO}_{2}+\mathrm{FeSO}_{4}$. J. Nano-Electron. Phys. 9: 03016.

16. Friend R H and Yoffe A D, 1987. Electronic properties of intercalation complexes of the transition metal dichalcogenides. Adv. Phys. 36: 1-94.

17. Stoynov Z B, Grafov B M, Savova-Stoynova B and Elkin V V. Electrochemical impedance. Moscow: Nauka (1991).

18. Barsoukov E and Macdonald J R. Impedance spectroscopy: theory, experiment, and applications. John Wiley \& Sons (2005).

19. Luryi S, 1988. Quantum capacitance devices. Appl. Phys. Lett. 52: 501.

20. Bisquert J, Randriamahazaka H and Garcia-Belmonte G, 2005. Inductive behaviour by chargetransfer and relaxation in solid-state electrochemistry. Electrochim. Acta. 51: 627-640.

21. Mora-Seró I, Bisquert J, Fabregat-Santiago F, Garcia-Belmonte G, Zoppi G, Durose K, Proskuryakov Y, Oja I, Belaidi A, Dittrich T, Tena-Zaera R, Katty A, Lévy-Clément C, Barrioz V and Irvine S J C, 2006. Implications of the negative capacitance observed at forward bias in nanocomposite and polycrystalline solar cells. Nano Lett. 6: 640-650.

22.Ivashchyshyn F, Grygorchak I, Stakhira P, Cherpak V and Micov M, 2012. Nonorganic semiconductor - conductive polymer intercalate nanohybrids: fabrication, properties, application. Curr. Appl. Phys. 12: 160-165.

23. Bishchaniuk T M, Grygorchak I I, Fechan A V and Ivashchyshyn F O, 2014. Semiconductor clathrates with a periodically modulated topology of a host ferroelectric liquid crystal in thermal, magnetic, and light-wave fields. Tech. Phys. 59: 1085-1087.

24. Pollak M and Geballe T H, 1961. Low-frequency conductivity due to hopping processes in silicon. Phys. Rev. 122: 1742.

25. Valov I, Linn E, Tappertzhofen S, Schmelzer S, Van Den Hurk J, Lentz F and Waser R, 2013. Nanobatteries in redox-based resistive switches require extension of memristor theory. Nature Commun. 4: 1771.

Dupliak I., Ivashchyshyn F., Całus D., Seredyuk B., Chabecki P., Maksymych V. and Fengping Li. 2020. Influence of optical radiation and magnetic field on the properties of $\operatorname{InSe}<\mathrm{NaNO}_{2}>$ clathrate. Ukr.J.Phys.Opt. 21: 115 - 125 doi: 10.3116/16091833/21/3/115/2020

Анотація. Досліджено зміни, що відбуваються у фізичних властивостях монокристалів InSe внаслідок інтеркаляиіï $\mathrm{NaNO}_{2}$. Проаналізовано ступінь розширення кристалічної тратки. Досліджено властивості вихідних монокристалів InSe та двократно або чотирикратно розширених кристалів. Крім того, проаналізовано вплив квантової ємності на процес проходження струму для двократно розширеного клатрату InSe $<\mathrm{NaNO}_{2}>$ niд впливом постійного магнітного поля. Вивчено вплив «негативної ємності» на низьких частотах магнітного поля в двократно розширеному клатраті InSe $<\mathrm{NaNO}_{2}>$ в умовах освітлення. 